\title{
Escoliose e Cifose de Scheuermann: o trajeto da documentação museológica de coleções arqueológicas no Museu de Arqueologia e Etnologia da Universidade Federal da Bahia
}

\author{
Scoliosis and Scheuermann Kyphosis: the path of museological documentation of \\ archaeological collections at the Museum of Archeology and Ethnology of the Federal \\ University of Bahia
}

\begin{abstract}
Luciana Messeder Ballardo
Doutoranda do Programa de Pós-Graduação em Museologia e Patrimônio pela Universidade Federal do Estado do Rio de Janeiro - UNIRIO, Brasil. Professora Assistente do Departamento de Museologia da Faculdade de Filosofia e Ciências Humanas da Universidade Federal da Bahia - UFBA, Brasil. https://orcid.org/0000-0002-2005-524X E-mail: 1mb@ufba.br

Elizabete de Castro Mendonça Doutora em Artes Visuais pela Universidade Federal do Rio de Janeiro - UFRJ, Brasil. Professora Associada do Departamento de Estudos e Processos Museológicos e do Programa de Pós-Graduação em Museologia e Patrimônio da Universidade Federal do Estado do Rio de Janeiro - UNIRIO, Brasil.

https://orcid.org/0000-0003-4913-1872 E-mail: elizabete.mendonca@unirio.br
\end{abstract}

\section{Resumo}

Esta pesquisa integra o trabalho de doutorado "Gestão de coleções arqueológicas musealizadas: dos métodos de campo à documentação museológica", vinculada ao Programa de Pós-Graduação em Museologia e Patrimônio da Universidade Federal do Estado do Rio de Janeiro (PPGMUS-UNIRIO), e tem como objetivo analisar quais critérios podem orientar propostas de requalificação ou substituição de sistemas documentais em instituições museológicas que incorporam coleções arqueológicas. A abordagem desenvolveu-se por meio de análise comparativa da formação das coleções e do percurso da documentação museológica. Preliminarmente, evidenciouse que os diagnósticos dos sistemas antecessores desconsideraram as especificidades das coleções arqueológicas e a falta de enlace entre os profissionais de Arqueologia e Museologia resultaram numa documentação museológica que não apresenta informações significativas para a investigação arqueológica.

Palavras-chave: Documentação. Museu. Arqueologia.

\begin{abstract}
This research is part of the doctoral work "Management of musealized archaeological collections: from field methods to museological documentation", linked to the Graduate Program in Museology and Heritage at the Federal University of the State of Rio de Janeiro (PPGMUS-UNIRIO), and aims to analyze what criteria can guide proposals for documentary systems requalification or replacement in museological institutions which incorporate archaeological collections. The approach was developed through a comparative analysis of the collections' formation and the museological documentation route. Preliminarily, it was evident that the diagnoses of the predecessor systems disregarded the specificities of the archaeological collections and the lack of connection between the professionals of Archeology and Museology resulted in a museum documentation that does not present significant information for the archaeological investigation.
\end{abstract}

Keywords: Documentation. Museum. Archeology. 


\section{Introdução}

Coleções arqueológicas não estão isoladas dentro de instituições. Normalmente as distintas tipologias de coleções dividem os espaços com temática científica, histórica ou outra afim, e em muitos casos o primeiro sistema documental não abrange as especificidades delas. Assim, é natural que, com o crescimento das coleções e o desenvolvimento científico, os sistemas de documentação museológica sofram alterações e até substituições.

O problema central, no entanto, é saber se as requalificações aplicadas ponderam sobre a inserção dos dados gerados durante a investigação arqueológica, organizando-as de forma coerente para o campo de pesquisa da Arqueologia, ao mesmo tempo que buscam desenvolver as potenciais relações entre a Museologia e a Arqueologia.

Os profissionais que tratam da documentação do patrimônio arqueológico vão se deparar em algum momento com problemas como o grande volume de material, cujo aumento é exponencial, sem a certeza de como agrupá-lo aos dados advindos das pesquisas depositadas na instituição. Além disso, há uma grande possibilidade de se defrontarem com situações em que tipos diferentes de coleções, tais como etnológicas e arqueológicas, apresentem desequilíbrio quantitativo - centenas de uma e milhares da outra.

Ainda assim, as instituições contam com sistemas documentais implantados em sua fundação utilizando uma sistematização única para todas as coleções. Isso porque, até certo momento pode ser que não houvesse grandes discrepâncias quantitativas ou de dados prévios.

Isso posto, o objetivo desta pesquisa é compreender quais critérios podem orientar propostas de requalificação ou substituição de sistemas documentais em instituições museológicas que incorporam coleções arqueológicas. A metodologia aplicada para o estudo foi uma análise comparativa da formação de coleções e da trajetória da documentação no Museu de Arqueologia e Etnologia da Universidade Federal da Bahia (MAE/UFBA) ${ }^{1}$. Nesse sentido, utilizou-se uma analogia entre patologias que acometem a coluna vertebral e os problemas encontrados na gestão e documentação do patrimônio arqueológico incorporado pela instituição.

A coluna vertebral protege a medula e os nervos, serve de base estrutural para o corpo e é responsável pela movimentação de seus membros. Assim como a coluna vertebral, a

\footnotetext{
${ }^{1} \mathrm{O}$ museu é um dos estudos de caso da pesquisa de doutorado cujos dados aqui apresentados constarão na tese.
} 
documentação protege as coleções e as informações sobre elas e é essencial na manutenção da segurança dos objetos. Serve como base para outras ações, como as de pesquisa, conservação e comunicação, e tem um papel essencial na movimentação das coleções, principalmente na proposição de exposições e ações educativas.

Informações sobre os artefatos, presentes em fichas de registros e outros instrumentos documentais, podem ajudar na identificação das peças e no controle das coleções, assim como na organização e no acondicionamento, seja em Reserva Técnica, seja em exposições.

Dados relacionados a estrutura e material de composição podem auxiliar nas decisões sobre os procedimentos de documentação a serem aplicados, enquanto os associados ao contexto e aos antecedentes servem como base de pesquisas, tanto para o trabalho de comunicação na instituição quanto como fonte de investigação acadêmica.

O discurso expográfico e as condições de conservação embasam as decisões sobre a transferência dos objetos de áreas internas para públicas dentro do museu ou para outra instituição, que são registradas em instrumentos documentais, tais como fichas de registro.

A diferença no ritmo de crescimento das vértebras como ocorre na cifose de Scheuermann ou as curvaturas anormais apresentadas na escoliose, por exemplo, podem imprimir deformidades na coluna, detectadas por exames de imagem. De qualquer forma, em ambos os casos, essas imperfeições podem causar obstáculos no desempenho de suas funções. A partir dessa analogia as discussões serão direcionadas para os dois tipos de alterações na espinha dorsal do MAE/UFBA, através da formação e expansão das coleções e da análise das atividades de documentação.

Posteriormente, o texto aponta para questões de linguagens terminológicas e a relação entre diferentes áreas do conhecimento, ocasionando dificuldades para a comunicação entre os campos científicos arqueológico e museológico. 


\section{A coluna vertebral como fonte de informação}

A coluna vertebral é parte de um todo: o corpo humano. Portanto, quando surgem problemas, por exemplo, na coluna cervical, isso pode afetar outras partes do corpo ocasionando sintomas como "cefaleia, zumbidos, ânsia de vômito, dores na face, pescoço, ombro e membros superiores, além de dores na frente do tórax, como também formigamento e adormecimento nos braços, mãos e dedos". Por isso, ao realizar o diagnóstico, o especialista não deve se descuidar do conjunto, ao analisar o histórico do paciente, realizar os exames físico e laboratoriais, para assim compreender o quadro clínico (KNOPLICH, 2016, p. 76).

Para a Arqueologia são importantes, além dos artefatos, os dados adquiridos através da disposição espacial, da maneira ocupacional e da escolha geológica do espaço; portanto, o sítio arqueológico não se resume a um repositório da cultura materializada em objetos. Também não é um resíduo incólume de ocupações anteriores, mas o resultado de um conjunto de processos sucessivos que "ocorrem durante a vida do local, depois no ponto de abandono, e continua como processos contínuos naturais e culturais” (DREWETT, 1999, p. 30, tradução nossa). Da mesma forma, a documentação das coleções incorporadas por um museu é mais que um repositório de dados e deve considerar todas as importantes informações que fazem parte da pesquisa arqueológica no processo documental das coleções.

Cada realidade presente nas distintas ocupações possui um sentido organizacional intrínseco, "como territórios de códigos munidos de suas especificidades". Esse sentido permeia as ideias e práticas, os conceitos e tradições, e compõe o "meio-ambiente de obtenção e de transmissão da forma de simbolização", promovendo as alterações que ocorrem no coletivo social (LIMA, 2008, p. 34). De maneira semelhante, os distintos processos de criação e execução de sistemas documentais museológicos possuem um sentido organizacional intrínseco próprio para o grupo de trabalho que o criou a partir das demandas advindas das relações estabelecidas com as demais atividades da gestão museológica e, a partir das inter-relações das coleções, cujas especificidades demandam informações inerentes a complexidade de cada tipologia.

Essas relações estabelecidas são como teias entrelaçadas a partir da ideia de que "um acervo deve gerar informação e, consequentemente, proporcionar uma melhor interação entre instituição, seus profissionais, pesquisadores e visitantes” (MENDONÇA, 2012, p. 11). As teias também tornam a documentação algo dinâmico, que passa por transformações sempre que 
necessário, cujo ritmo é indicado pela incorporação de coleções ou pelo processo museológico - valorização seletiva, salvaguarda e comunicação - bem como nos procedimentos a eles integrados (BALLARDO; MENDONÇA, 2018).

A documentação do patrimônio arqueológico não está relacionada apenas ao conhecimento interdisciplinar, mas a "aplicações (contextos, áreas, setores, organismos), isto é, a informação científica, tecnológica, industrial ou artística, ou a aplicação em campos do conhecimento", como a Museologia (PINHEIRO, 1999, p. 176). Dessa forma, mais do que “[...] tratar o objeto arqueológico musealizado como fonte de informação e articular conhecimentos destas áreas afins", as vinculações entre dois campos através das aplicações devem pressupor o próprio patrimônio arqueológico, incluindo o sítio e os seus diferentes contextos e ocupações como matriz informacional, "com a finalidade de diminuir a possibilidade de interpretação equivocada, potencializando o acervo como indicador de memória” (MENDONÇA, 2012, p. $11)$.

O conhecimento produzido na área de documentação como fonte de informação remonta, na área de Museologia, um período que abrange cerca de quarenta anos ${ }^{2}$, enquanto as pesquisas direcionadas mais especificamente para a documentação e gestão de coleções arqueológicas, dentro do campo museológico, são mais recentes ${ }^{3}$. A gestão e documentação museológica de coleções arqueológicas devem estar mais relacionadas à elaboração e práxis de sistemas documentais que considerem e tratem dos dados obtidos na pesquisa arqueológica como um todo e suas fontes de informação, em geral, não apenas o material coletado.

A contribuição desse trabalho está na análise das reestruturações nos sistemas documentais, a partir do crescimento das coleções, e das mudanças relacionadas ao modo de aquisição, além das inter-relações no universo da gestão museológica no decorrer do tempo.

2 Dentre esses, podem ser citados: ICOM/UNESCO, 1970, Camargo-Moro, 1986, Ferrez; Bianchini,1987, Ferrez, 1994, Cândido, 2002, Bottallo, 2010 e Padilha, 2014.

3 Tais como: Bottallo, 1998, Raposo; Martins; Correia, 2000, Santos, 2015 e Caldarelli; Cândido, 2017. 


\section{O museu e as coleções - cifose de Scheuermann}

Onze anos: esse foi o intervalo de tempo entre a inauguração, em 27 de setembro de 1983 (PEREIRA, 2014), e a legitimação, em 07 de abril de 1995 (UNIVERSIDADE FEDERAL DA BAHIA, 1995) ${ }^{4}$, do Museu de Arqueologia e Etnologia da UFBA, posto que a instituição não contava com documentos jurídico-administrativos que o oficializassem. Durante esse período inicial, além do próprio sítio arqueológico que acolhe o MAE-UFBA ${ }^{5}$, as coleções arqueológicas eram formadas por um total de 382 artefatos e as etnológicas, de 293, ordenadas conforme a Tabela 1 .

Tabela 1 - Identificação e quantitativo das coleções incorporadas ao MAE no processo inicial de formação

\begin{tabular}{|l|l|l|l|}
\hline \multicolumn{2}{|c|}{ Coleções arqueológicas } & \multicolumn{2}{c|}{ Coleções etnológicas } \\
\hline Nome & Quantidade & Nome & Quantidade \\
\hline Vital Rego & 61 & Pedro Agostinho & 268 \\
\hline Carlos Ott & 15 & Pankararé & 12 \\
\hline Valentin Calderón & 261 & Tuxá & 13 \\
\hline Projeto Sobradinho de Salvamento Arqueológico & 46 & & \\
\hline
\end{tabular}

Fonte: Elaborado pela autora 1 com base em Alcântara (2016) e Passos (2016).

De todas essas coleções arqueológicas ${ }^{6}$, apenas a do Projeto Sobradinho adveio de pesquisa interventiva (ALCÂNTARA, 2016), enquanto as de Etnologia ${ }^{7}$, a de Pedro Agostinho ${ }^{8}$ e dos Tuxá são provenientes de estudos acadêmicos e a do Projeto de Salvamento Itaparica da CHESF derivado de licenciamento ambiental (PASSOS, 2016).

Na década seguinte, a coleção de Aristóteles Barcelos Neto e Maria Ignês Mello9 , contendo 227 peças, é agregada ao museu, totalizando as 520 peças que ainda compõem o acervo de Etnologia (ALMEIDA, 2019). Por outro lado, com o advento da Arqueologia de

4 Aprovada pelo Conselho Universitário da UFBA (1995), após a gestora do museu, Ana Gantois, através de expediente em 17 de novembro de 1992, ter solicitado, com urgência, a aprovação do Regimento Interno da entidade com o objetivo de regulamentar sua condição.

5 O subsolo do prédio da Faculdade de Medicina, no Pelourinho, que abriga a instituição desde sua criação, em 1983, também integra o patrimônio arqueológico a ele incorporado por ser um sítio que passou por intervenção em 1975, coordenada por Calderón (SOARES; ETCHEVARNE; MENDONÇA, 2006; SANTOS, 2014).

6 As coleções iniciais de Arqueologia foram designadas com o nome de seus colecionadores. Suas coletas não foram realizadas por pesquisa interventiva, como é o caso das coleções de Vital Rego, Carlos Ott e Valentin Calderón, adquiridas por compra ou doação. A partir da pesquisa interventiva de Sobradinho, as coleções passaram a receber o nome do projeto ou do sítio arqueológico (sendo esse o caso) ao qual foram vinculadas.

7 Das quatro coleções etnológicas do MAE/UFBA, duas receberam o nome de pesquisadores envolvidos na investigação e com coletas de campo vinculadas a pesquisas acadêmicas: Pedro Agostinho e Aristóteles Barcelos; e duas o nome da etnia que elaborou as peças pertencentes ao acervo: os Tuxá e os Pankararé.

8 Pesquisa de mestrado em Antropologia da Universidade de Brasília.

9 Resultado das pesquisas de mestrado em Antropologia Social da Universidade Federal de Santa Catarina. 
Contrato, as coleções aumentaram descomunalmente e a estimativa atual é que o quantitativo ultrapasse duzentos mil artefatos e fragmentos depositados no órgão (ALCÂNTARA, 2016).

Por quase uma década e meia, o MAE/UFBA não recebeu novas coleções e desde sua criação até esse período o acervo contabilizava 675 peças. Entre 1997 e 2014, foi realizado um total de 69 projetos acadêmicos e de licenciamento ambiental. Nesse ínterim, houve dois picos no ingresso de coleções conforme visualizado no Gráfico 1.

Gráfico 1 - Quantitativo de pesquisas endossadas pelo museu x ano

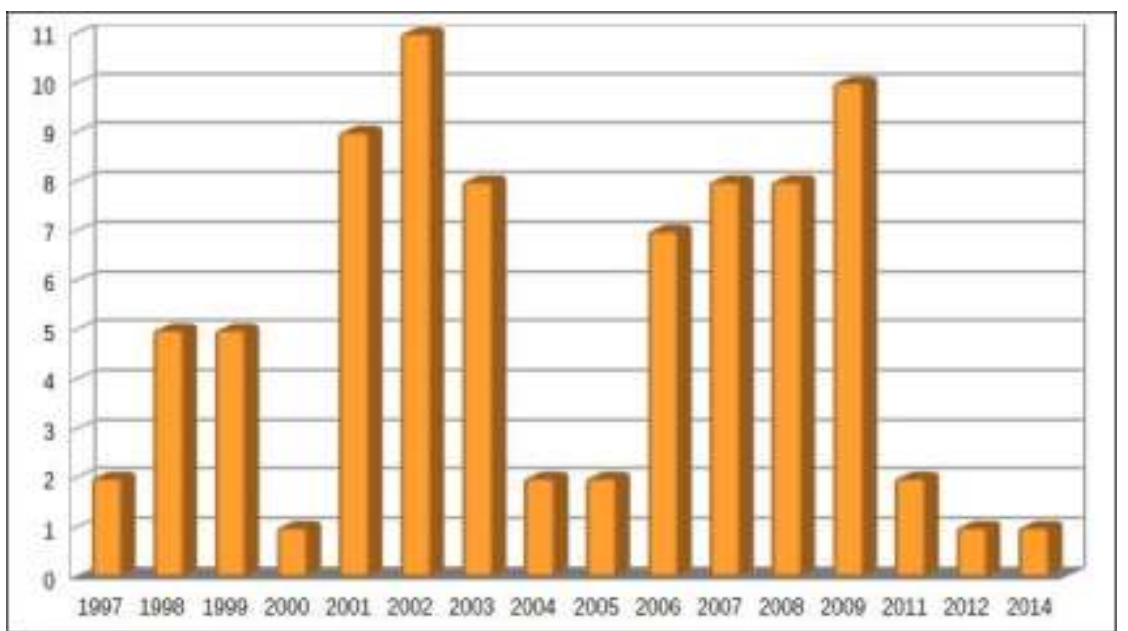

Fonte: Criado pela autora 1 com base nos dados cedido pelo setor de Arqueologia do MAE/UFBA (2020).

Apenas depois da legalização da entidade, em 1995, outras coleções foram depositadas na instituição. Enquanto a de Etnologia recebeu pouco menos de 300, as de Arqueologia somaram, desde então, em torno de 200 mil.

Gráfico 2 - Períodos de ingresso de coleções arqueológicas

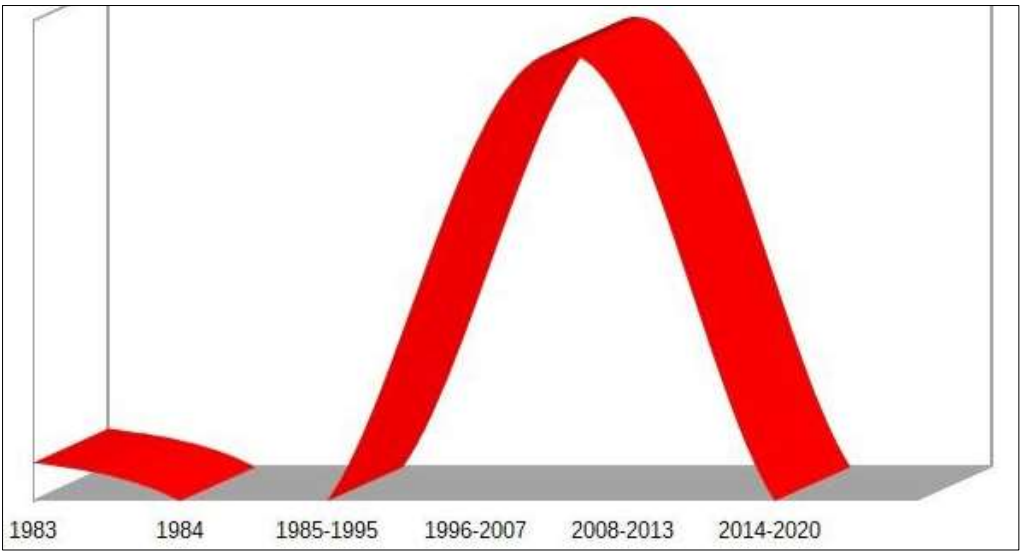

Fonte: Elaborado pela autora 1 (2020).
Figura 1 - Imagem de Raio-X de Cifose de Scheuermann

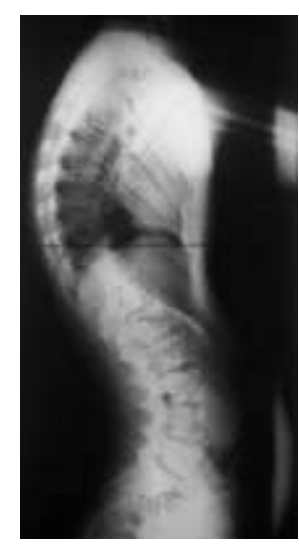

Fonte: Natour, 2004, p. 177. 
Considerando o ingresso de material arqueológico num panorama mais geral, depois das quatro primeiras coleções que ingressaram em 1983 seguiu-se um período de ausência até 1996, com um posterior aumento massivo de coleções de 1997 a 2014, conforme Gráfico 2.

É possível observar que a linha de desenvolvimento das coleções, cujo crescimento é descomunal, tem um formato que lembra o de uma cifose na coluna (Figura 1), conhecida como corcunda. Isso obrigou a instituição a usar espaços extraterritoriais, inicialmente dentro do próprio prédio da Faculdade de Medicina e posteriormente em salas cedidas por outra instituição federal, visto que o próprio espaço do museu não comporta esse volume.

A cifose pode ser estrutural ou flexível. Um exemplo de cifose estrutural é a de Scheuermann, desenvolvida na puberdade, por abaulamento em forma de cunha de uma ou mais vértebras adjacentes. Dentre seus sintomas apresenta os nódulos de Schmorl (hérnias do disco não vertebral através da placa terminal adentro do corpo vertebral) e o desvio nas placas terminais (composta por uma espessa camada de cartilagem entre o disco invertebral e o osso esponjoso do corpo vertebral), além de uma leve $\left(10^{\circ}\right.$ a $\left.20^{\circ}\right)$ escoliose (curva na coluna visível de frente ou de costas) em até 30\% dos casos (NATOUR, 2004).

A documentação museológica, assim como as placas terminais, podem servir para amortecer os impactos advindos do próprio uso e gestão das coleções, acentuados pela desproporção de ingresso delas. Contudo, no MAE/UFBA, a irregularidade nas atividades de documentação pode ser comparada aos desvios na espinha. Um exemplo disso é a pausa de cerca de um ano entre o final do uso de um sistema de documentação e o início do próximo que se configurou como um nódulo de Schmorl, quando a equipe responsável pela nova documentação adentra no espólio do Centro de Documentação (CD/MAE).

Essas questões, somadas à suspensão de incorporação de coleções em 2014 e à admissão de uma arqueóloga no quadro da instituição, tornaram a gestão de coleções o foco para o museu. Mas, para realizar essa tarefa, faz-se necessário compreender como a instituição já realizava essa atividade ao longo de todos esses anos de existência. 


\section{Escoliose: a documentação no âmbito museológico}

Um dos principais problemas relacionados à gestão de coleções arqueológicas da instituição diz respeito ao percurso da documentação do acervo desde a criação do Museu. Isso ocorreu, inicialmente, devido à dificuldade em dar continuidade ao processo documental de forma que, após o ingresso do artefato, seu trajeto posterior não era documentado ${ }^{10}$.

Durante a pesquisa não foram encontradas menções ou documentos que atestassem a existência de protocolos e diretrizes ${ }^{11}$ em qualquer das tentativas de requalificar ou constituir um sistema de registro, sobretudo relativo às coleções arqueológicas, aos mecanismos de ingresso ou à clareza quanto aos parâmetros usados na escolha desses sistemas. Contudo, sempre que se buscou criar uma nova sistematização da documentação, ela foi precedida por um diagnóstico do trabalho realizado anteriormente. Essas avaliações auxiliaram nos projetos implantados posteriormente, no entanto nem sempre consideraram as necessidades introduzidas com o ingresso de coleções incorporadas por endosso institucional.

O primeiro processo de documentação do acervo museológico da instituição remonta ao ano de abertura do museu, sob incumbência do professor Osvaldo Gouveia e de estudantes de Museologia da universidade (SANTOS, 2014). Nesse período, o sistema de documentação foi implantado nas coleções arqueológicas e etnológicas sem distinção de especificidades, a partir das três ferramentas que o compunham: o esboço do livro de inventário, a marcação dos artefatos e as fichas de registro. $\mathrm{O}$ sistema de numeração foi criado do seguinte modo:

a. Três algarismos arábicos correspondentes aos últimos dígitos do ano de entrada;

b. Dois números romanos que determinam a coleção à qual o objeto pertence;

c. Numeração corrida em arábico identificando cada artefato dentro da coleção.

Na ficha de registro, a distinção não foi adotada no número de identificação. Aplicouse a partir de outros metadados, como por exemplo o número de catálogo arqueológico, que advém de uma sistematização do responsável pela coleta e pesquisa do material. Também foi feita a inclusão de duas metainformações que propunham uma linguagem mais específica da

10 Esse fator está diretamente conectado com os vácuos temporais entre a implementação e as requalificações (a primeira entre 1996 e 2002 e a última entre 2004 e 2007) que a princípio parecem ter uma relação íntima com o processo de incorporação das coleções, sobretudo as arqueológicas, retomadas no final da década de 1990.

11 A Portaria No 7 de 1988 do Ministério da Cultura (MINC)/Serviço do Patrimônio Histórico e Artístico Nacional (SPHAN) (BRASIL, 1988) é o único documento usado como referência para o ingresso de coleções e determina que a documentação gerada na pesquisa arqueológica deve ser depositada apensa ao material coletado 
Arqueologia: artefato, substituindo o termo objeto, e origem e/ou sítio arqueológico, que sinalizou um termo alternativo ao usual da esfera museológica.

Por outro lado, foi incluída uma metainformação que parece mais condizente com a terminologia etnológica, o de grupo cultural ou étnico, visto que na Arqueologia é mais usual para compreender a questão do contexto, o termo categoria do sítio arqueológico ${ }^{12}$.

Um metadado agregado foi o modo de aquisição. Isso porque, neste momento, boa parte da coleção, sobretudo a arqueológica, foi obtida por compra (Vital Rego) ou por doação (Valentin Calderón), e o universo de artefatos que sofreria uma explosão no quantitativo a partir de finais dos anos 1990, ainda era reduzido, não alcançando sequer quatro centenas.

Atualmente ${ }^{13}$, é mais lógico criar uma seção da ficha de registro para a coleção, onde os dados gerais como esses seriam respondidos. Como exemplo, a Coleção Vital Rego, com 61 artefatos, poderia ter apenas um metadado com esse item na seção da coleção e, caso houvesse alguma exceção, poderiam ser identificadas num campo sob o termo observações. ${ }^{14}$

A ficha de identificação criada pela primeira equipe que organizou a documentação museológica da instituição pode ser observada mais detalhadamente na imagem na Figura 2.

12 Nesse caso, seria possível responder se o sítio é pré-colonial, histórico ou de contato; ou, ainda, o tipo de ocupação (unicomponencial ou multicomponencial), fazendo uso da linguagem da ciência arqueológica e presente inclusive na atual ficha de registro do Cadastro Nacional de Sítios Arqueológicos, mantido pelo IPHAN.

13 Devido à quantidade de material incorporado por estudos acadêmicos e, em maior escala, por consultoria. 14 Mais informações sobre esse modelo de ficha de registro subdivido em seções, em Ballardo, 2013, p. 46. 
Figura 2 - Ficha de Registro de documentação do MAE/UFBA (frente e verso) de 1984

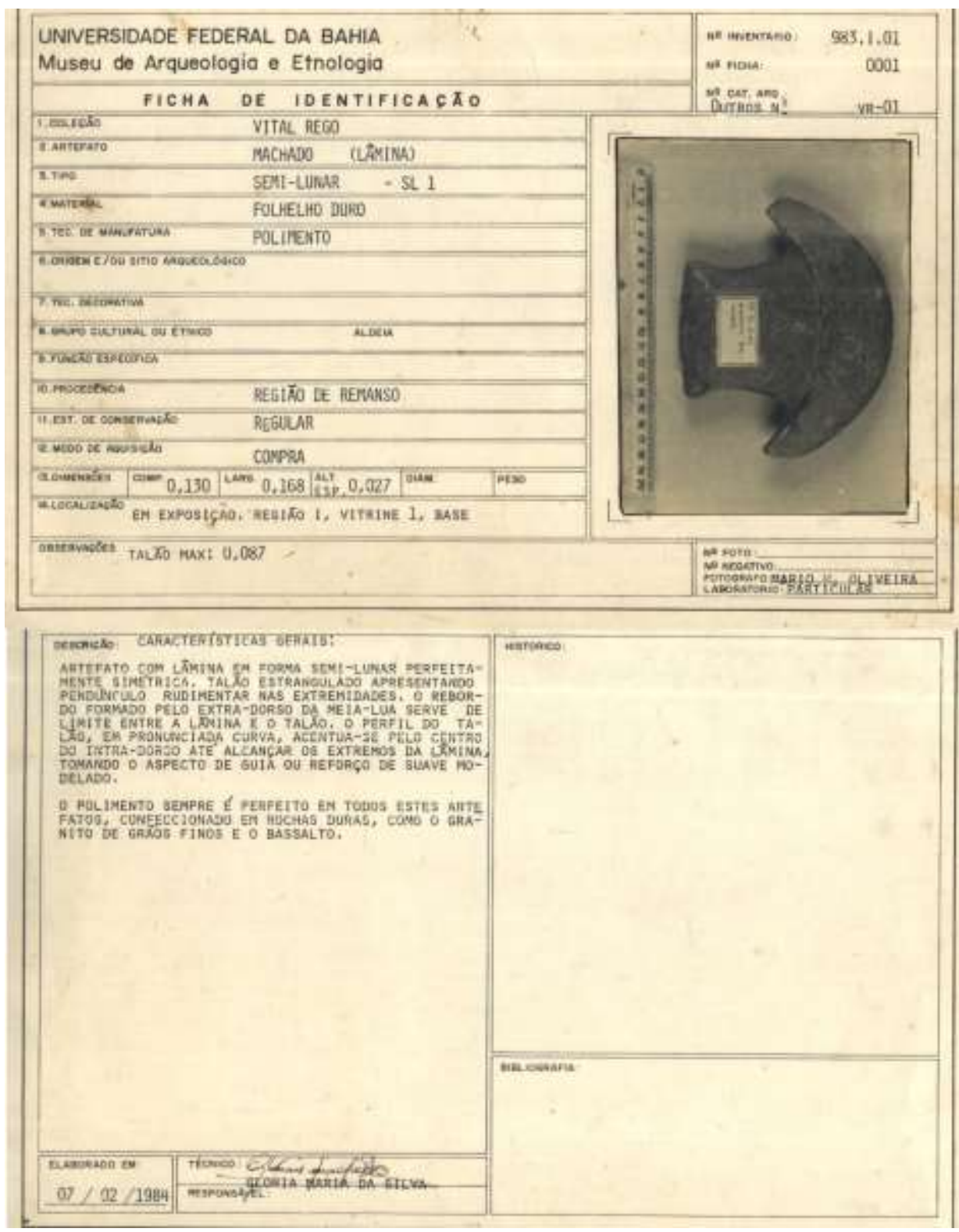

Fonte: Museu de Arqueologia e Etnologia da Universidade Federal da Bahia (2007).

A análise do primeiro sistema de documentação estabelecido em 1983 foi realizada com o propósito de encontrar falhas no sistema, não com o objetivo de substituição, mas como uma requalificação. Na primeira fase, que foi dedicada ao Projeto de Análise do Sistema Documental do Museu de Arqueologia e Etnologia da UFBa, no período de 1996 a 1998, o objetivo foi a realização de um diagnóstico do sistema de documentação das coleções museológicas da instituição, contanto com seis bolsistas, acadêmicos do curso de Museologia. Na etapa subsequente, com a realização do Projeto de Implantação do Centro de Documentação do Museu de Arqueologia e Etnologia da Universidade Federal da Bahia, entre 1998 e 2002, o objetivo foi a criação de um espaço para realização das atividades de documentação e a reestruturação do sistema de documentação museológica das coleções, com a participação de 
apenas quatro bolsistas. A responsável pela coordenação desses dois projetos foi a professora do Departamento de Museologia Rosana Nascimento (BRASÍlLIA, 2020, http://lattes.cnpq.br/4874268042003853).

Os resultados do diagnóstico realizado pelo Projeto de Análise do Sistema Documental do MAE/UFBA (1996 - 1998) acusaram problemas: no sistema de registro - artefatos sem número, com o desdobramento numérico ausente, com numeração repetida, segregados do sistema de registro ou com o número incognoscível; no inventário - ausência desse documento na instituição e falta do termo de abertura do esboço do livro de inventário; na marcação - uso de etiquetas de tecido ou adesivas, local inapropriado, ilegibilidade, ausência, excesso (duas ou mais), desdobramento ausente; na ficha de identificação - artefato com até três fichas distintas, discrepância terminológica e inexistência de vocabulário controlado (NASCIMENTO, 2004).

Na etapa subsequente ${ }^{15}$, à realização do Projeto de Implantação do Centro de Documentação do MAE/UFBA (1998 - 2002) ((BRASÍLIA, 2020, http://lattes.cnpq.br/3520955054532444), um novo sistema documental foi estabelecido para substituir o anterior, composto por um número maior de instrumentos de controle, entre eles a boneca de inventário realizada em 1997, listas de arrolamento do acervo, ficha de acervo (com identificação individual e breve descrição), ficha de identificação e ficha de identificação do acervo iconográfico (CERÁVOLO, 2008).

A maior contribuição desse trabalho especificamente para as coleções arqueológicas foi a elaboração de uma seção denominada Referências Arqueológicas, que, além de trazer dados

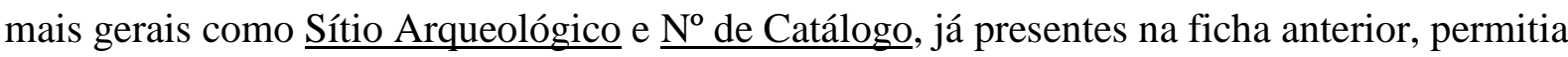
a inscrição de dados vitais para a pesquisa arqueológica relacionados ao seu contexto dentro do sítio, tais como Quadra, Subquadra/Setor e Nível, além de incluir o metadado Projeto, que poderia apontar onde encontrar documentação de caráter arqueológico relacionada ao artefato. Foi um pequeno passo para a documentação no MAE/UFBA, mas um grande passo para os estudos em gestão museológica de coleções arqueológicas.

15 É importante ressaltar que nesse mesmo período estavam ingressando coleções nas duas áreas de conhecimento abrangidas pela instituição, mas principalmente na Arqueologia. Foi um momento de crescimento rápido no quantitativo de peças, como nunca visto antes na história dessa instituição. 
Da mesma forma, o sistema numérico passou a ter um algarismo romano para designar a coleção e um número arábico corrido para o objeto isoladamente. Após esse número, seguese um sinal gráfico, o ponto, e em sequência o número zero ${ }^{16}$, conforme apresenta a Figura 3.

Figura 3 - Ficha de Registro de documentação do MAE/UFBA criada em 1999

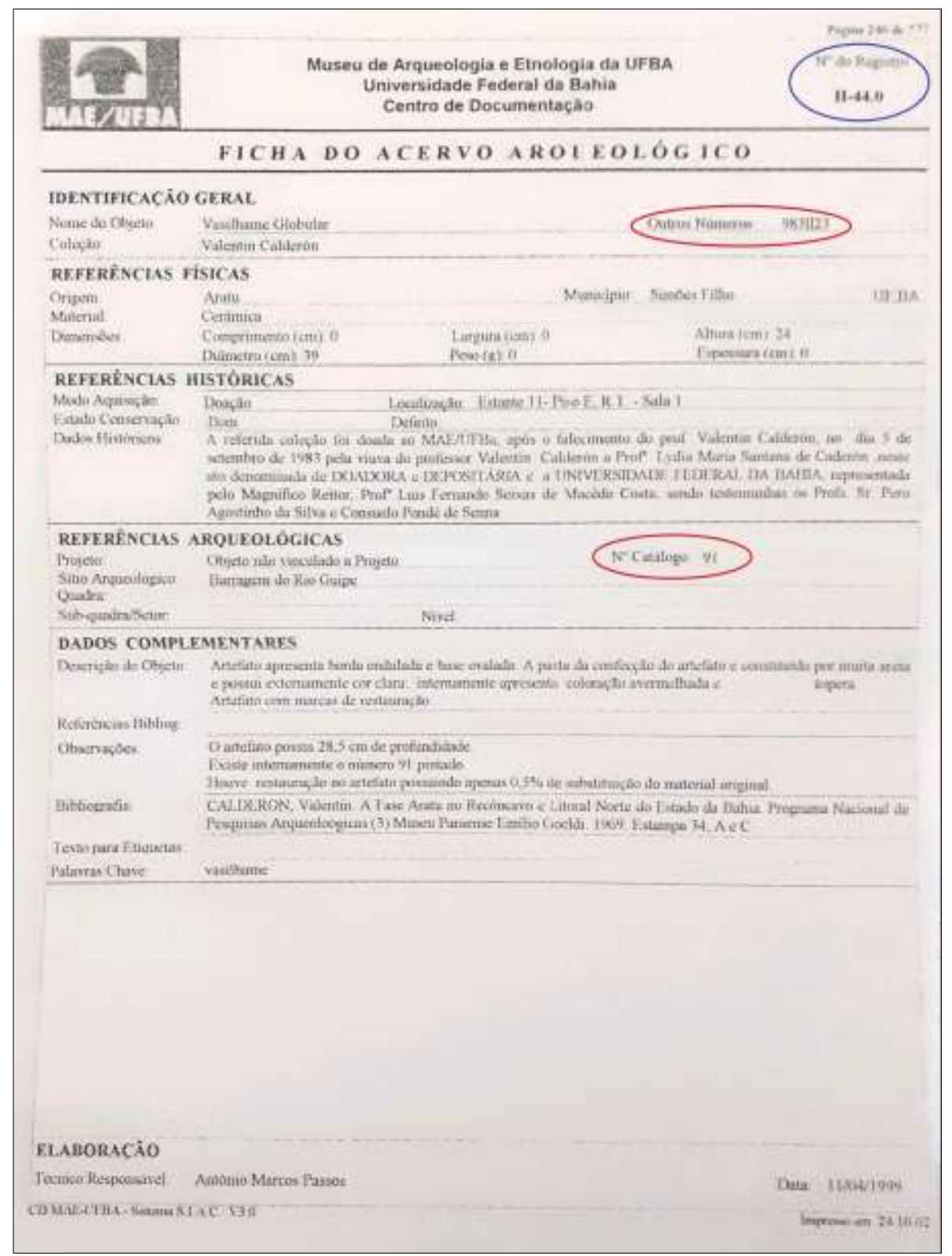

Fonte: Museu de Arqueologia e Etnologia da Universidade Federal da Bahia (2009).

Durante a pesquisa não foi possível identificar qualquer relação entre os números de catálogo da documentação na área arqueológica e no campo museológico, destacados na imagem acima com círculos vermelhos. Esse fato desencadeia um problema, visto que o

16 Embora requeira mais análises, o algarismo após o ponto parece ser utilizado para apontar a existência de subdivisões caso fosse formado por mais de uma parte ou houvesse partes de um conjunto. Por exemplo, um pilão e a mão do pilão formam um conjunto, enquanto dois fragmentos cerâmicos remontados podem tornar-se uma urna, sendo então duas partes de uma peça. 
número de catálogo, no âmbito da Arqueologia, corresponde não a um artefato, mas ao um conjunto deles, que podem estar relacionados por sua localização no sítio arqueológico, ou ainda por função ou tipologia. Dessa forma, um mesmo número de catálogo 91, como é o caso, corresponderia a números distintos de registro na documentação museológica, sendo difícil estabelecer uma relação entre eles.

Os avanços na documentação museológica incluíram também à estruturação de um espaço físico para a realização dos procedimentos documentais, isso ocorreu com a criação do CD/MAE. Nesse espaço foram elaborados instrumentos a fim de possibilitar a gestão de informações relacionadas ao acervo, como uma base de dados composta por um Banco de Dados Documental, um de Memória Oral e um Banco de Audiovisuais, possibilitando a informatização de todo o sistema. O propósito da base de dados era: "gerar fichas de catalogação, localização, inventários e índices remissivos"; armazenar e atualizar "dados descritivos e imagens", possibilitando a criação de catálogos de coleções; criar "índices remissivos por coleção, número de registro, material, procedência, sítio arqueológico"; estabelecer uma conexão entre o "acervo e o material bibliográfico disponível, facilitando os trabalhos de pesquisadores" (NASCIMENTO, 2004, p. 269 e 270).

No segundo semestre de 2001, Carlos Costa (estudante de graduação em Museologia/UFBA) propôs a criação de uma ficha de registro dos sítios arqueológicos ${ }^{17}$ (BRASÍLIA, 2020, http://lattes.cnpq.br/8375227365744890), como ferramenta adicional de documentação com o propósito de estabelecer uma inter-relação das coleções de imagens, com o subsídio inicial do Banco de Dados Iconográfico (1998/1999) do CD/MAE ${ }^{18}$, primeiramente ${ }^{19}$ aquelas relacionadas aos sítios de arte rupestre em duas coleções, a de Valentín Calderón e a da Associação de Arqueologia e Pré-História da Bahia (AAPHB), nas áreas de Sobradinho e de Itaparica, representadas respectivamente pelos algarismos romanos II e IV no sistema de documentação museológica.

A ficha de identificação de Sítios

17 Produto do trabalho final de graduação que recebeu o título "Elaboração de instrumento documental para registro de sítios das coleções arqueológicas do MAE/UFBA".

18 Devido ao extravio de documentação e à restrição de dados, foi preciso ir ao "arquivo e biblioteca do Instituto do Patrimônio Histórico Artístico Nacional (IPHAN); arquivo e biblioteca da FFCH/UFBA; biblioteca do MAE/UFBA; e biblioteca do Instituto Geográfico e Histórico da Bahia (IGHB)" (COSTA, 2007, p. 8).

$19 \mathrm{O}$ estudo foi ampliado para o universo de todas as coleções (ou investigações) arqueológicas depositadas no museu: I - Vital Rego; II - Valentín Calderón; III - Carlos Ott; VI - AAPHB (Sobradinho e Itaparica); e duas acrescentadas na década de 2000, que são IX - Praça da Sé e X - Piragiba. É importante ressaltar que o código em número romano corresponde à identificação da coleção do museu, não necessariamente de Arqueologia, a coleção V, por exemplo, denominada Pankararé (etnológica). Por isso, a numeração corrida não se refere ao tipo de coleção e sim à ordem de entrada na instituição. 
Arqueológicos ${ }^{20}$ foi elaborada com o intuito de ser vinculada a duas outras ferramentas criadas pela no Centro de Documentação - a Ficha de Registro do acervo arqueológico e a do iconográfico, parte do sistema de documentação - e de estabelecer um processo de retroalimentação de dados (COSTA, 2007).

Apesar de uma proposta significativa para o processo de documentação, não foram encontradas referências dentro do órgão que apontem para a consolidação no contexto do Centro de Documentação, seja vinculada à documentação museológica, seja durante o processo de criação de documentos na esfera arqueológica, pós-campo, quando da entrada no laboratório de Arqueologia para o processo de curadoria e análise.

Em 2003, a equipe de Nascimento já havia deixado o museu e as atividades relacionadas à gestão do acervo foram descontinuadas. A base de dados deixou de ser usada e o espólio foi depositado em um anexo ao Museu, no prédio da Faculdade de Medicina.

No ano de 2004, a gestão de informações foi implantada em consoante com uma conceituação proveniente da Arquivologia, tratando conjuntos de documentos segundo o propósito a que servem, baseando-se na ideia do "museu como órgão produtor de documentos o que traz para primeiro plano a trajetória institucional pelos mais diversos suportes que foram encontrados, dos quais faz parte também a formação de coleções e as fichas de registros de artefatos" (CERÁVOLO, 2007, p. 5).

Nessa perspectiva, a sistematização dos documentos do órgão passa a usar uma terminologia arquivística, como o $\underline{\text { Arranjo }}$ do arquivo institucional, criando séries, subséries e o fundo, tanto para documentos administrativos como para aqueles relacionados às coleções, fossem comprovantes de compra, fossem contratos de doação ou cadernos de campo, que são a parte da documentação de âmbito arqueológico que compõe o patrimônio incorporado pela instituição, sem a qual as coleções perdem o próprio sentido de existência.

Os resíduos do CD/MAE foram recuperados e levados para uma área interna, iniciando a criação e o desenvolvimento do Núcleo de Documentação e Referência do Museu, coordenado por Suely Moraes Cerávolo, que teve como premissa "compreender que - em primeiro lugar -

20 Recebe, em primeira instância, um registro numérico que identifica a coleção e o sítio, e possui sete seções: Referências do Sítio, que agrupa as informações identitárias e territoriais; Características do Sítio, relacionada à estrutura e ao material encontrado; Características da Área, correspondente aos fatores ambientais da área; Informações Arqueológicas, conjunto de dados sobre o processo de pesquisa e documentos de registros criados nesse processo; Informações Museológicas, grupo de informações colhidas na documentação através das ferramentas criadas no CD/MAE ou disponíveis para pesquisa em outros setores da instituição; Observações, dados que não constem nos outros campos; e Preenchimento, identificação do responsável técnico e da data. 
se faz absolutamente necessária a organização do acervo documental. Posteriormente é que se pode iniciar a verificação das coleções de artefatos" (CERÁVOLO, 2006, p. 37) e que entre os produtos alcançados está a elaboração do Guia do Arquivo Institucional MAE/UFBA, cujo sumário pode ser visualizado na Figura 4.

Figura 4 - Sumário do Guia e Manual de Instruções do Arquivo Institucional do MAE/UFBA criado em 2007

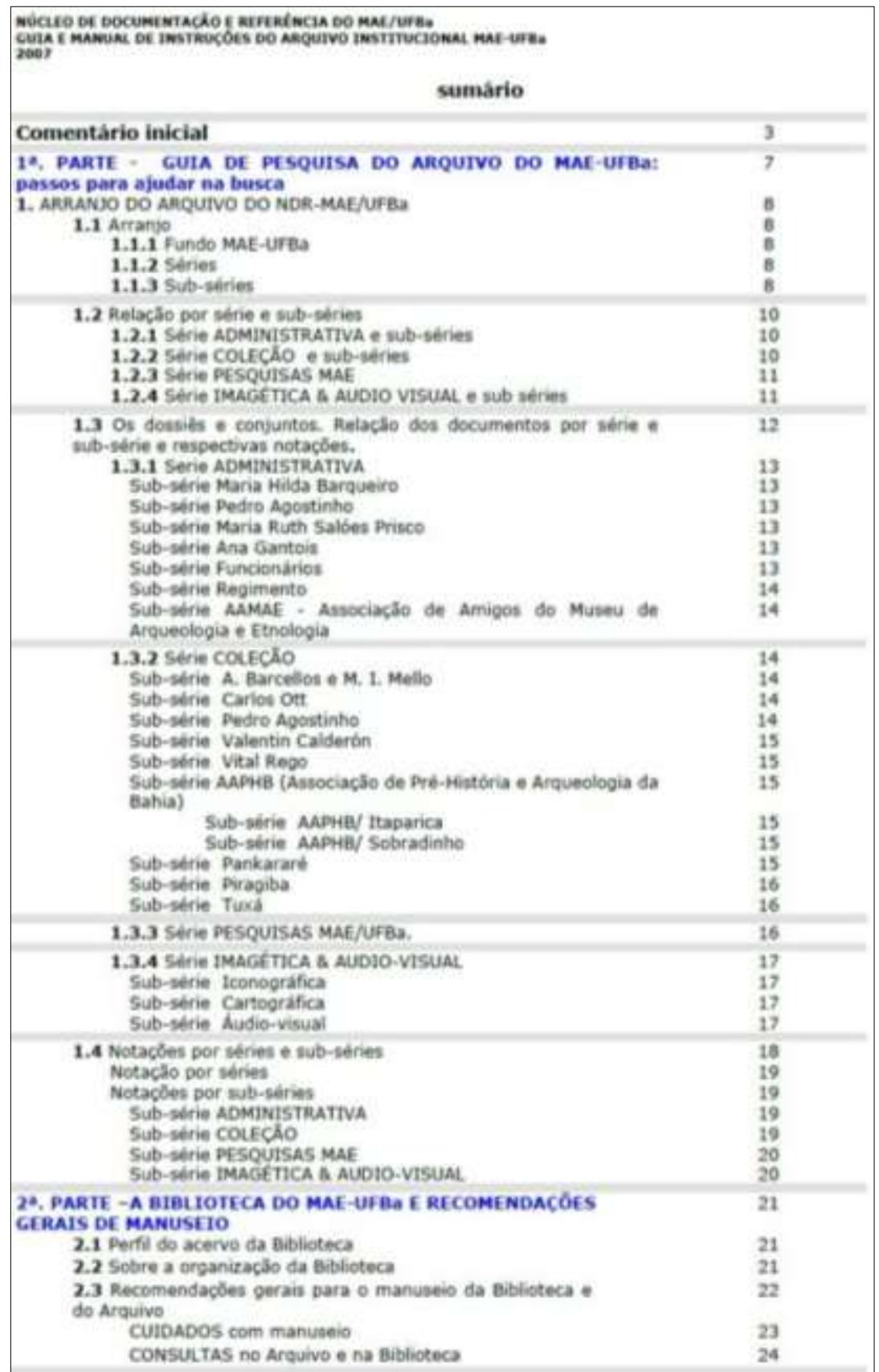

Fonte: Museu de Arqueologia e Etnologia da Universidade Federal da Bahia (2009). 
No entanto, essa perspectiva não atende a coleções musealizadas, uma vez que, o

objeto museal é o conceito que estamos denominando no contexto museológico, que significa a produção cultural (material e imaterial) do homem, os sistemas de valores, símbolos e significados, as relações estabelecidas entre os homens, entre o homem e a natureza, que através da modificação da natureza, cria objetos no decurso da sua realização histórica. São os objetos elaborados e existentes fora do homem, mas que refletem as complexas teias de relações entre os homens no processo histórico (NASCIMENTO, 1994, p. 10 e 11).

Os objetos são representações dessas relações sociais num dado contexto, e portanto, também são registros, fontes de informação e de conhecimento. Por exemplo, o selo real do rei Ezequias, governante de Judá no século VII A.C., é uma fonte de informação, que traz dados sobre um fato, a assinatura e autenticidade dos documentos marcados pelo artefato, através da inscrição "Pertencente a Ezequias, filho de Acaz, rei de Judá." O objeto é uma das muitas representações das relações presentes de um homem assinando documentos. Mas não é apenas isso! O selo se torna fonte de conhecimento quando passa a ser indagado, questionado na tentativa de estabelecer relações entre as muitas informações contidas nele. Que homem é esse? O que, ou quem, ele representa? Por que seu selo é feito de argila? Que tipo de documentos ele assina? Por quê? O que representam esses documentos?

A documentação museológica que classifica e registra informações também é uma representação, e portanto, quando é aplicada a um objeto museológico, ela se torna uma representação de outra representação. Toda documentação museológica sobre o selo usado pelo rei Ezequias é uma representação do selo; ele, o selo, por sua vez, é uma representação do objeto museal , a saber, as relações estabelecidas nos contextos, com os objetos e entre os humanos ali presentes.

Em 2007, no período de conclusão do trabalho da equipe supervisionada por Cerávolo (BRASÍLIA, 2020, http://lattes.cnpq.br/3520955054532444), mais especificamente no âmbito da documentação de coleções arqueológicas, foram elaboradas duas outras ferramentas: o Inventário de Coleções Arqueológicas do MAE/UFBA ${ }^{21}$ e o Inventário da Coleção Arqueológica Valentin Calderón no MAE/UFBA ${ }^{22}$. Nesse mesmo ano, a coleção Calderón passou por um processamento documental, usando como ferramentas a Planilha de Inventário e a Etiqueta para Identificação das Caixas de Acondicionamento das Coleções Arqueológicas.

21 Com a participação de Cinthia Cunha (bolsista) e Antônio Varjão, Hilda Bárbara Cesário, Lúcia Helena Ferreira (estudantes de Museologia/UFBa), Breno Carvalho (graduando Ciências Sociais/UFBa), Leandro Max (antropólogo), Teresa Cristina Mendonça (odontóloga), Antonio Carlos Nascimento (técnico em Arqueologia), Marcélia Marques (doutoranda em Arqueologia, PUC-RS), cujo objeto de estudo aborda também a Coleção Calderón) na "fase de processamento das coleções" (CERÀVOLO, 2008, p. 3 e 4).

22 Pesquisa vinculada ao trabalho de conclusão em Museologia do pesquisador Antônio Varjão. 
Além disso, foram realizados os procedimentos de higienização, quantificação e identificação (por lotes de fragmentos) em sacos e caixas e acondicionamento na Reserva Técnica; na exposição, as peças foram registradas em fotografias, identificadas e listadas com dados sobre suas localizações.

Nesse sentido, a metodologia aplicada foi a inserção de toda a documentação, seja arqueológica, tais como relatórios, cadernos de campo, identificação de fotos e negativos, realizada por anotações do pesquisador, ou museológica, como as bonecas de inventário e documentos de doação, no Dossiê Valentín Calderón, como subsérie da série Coleção.

Entre 2008 e 2012 (último ano que gerou material), as coleções arqueológicas incorporadas não foram processadas em termos de documentação museológica. Nesse período, a documentação do patrimônio arqueológico existente no museu é aquela gerada pelo pesquisador antes, no decurso e depois das intervenções e depositada junto com o material. Em 2011, o acervo arqueológico, que estava salvaguardado em salas anexas ao museu, foi desalojado e remetido para um prédio administrativo do Instituto Federal da Bahia para guarda temporária do material, por meio de um acordo com a universidade (VASCONCELOS; ALCÂNTARA, 2017).

Entre 2013 e 2014, ocorreu a mudança das coleções da quadra de esportes para quatro salas (em decurso de decomposição), acontecimento que originou o Projeto de Requalificação da Reserva Técnica do MAE/UFBA ${ }^{23}$, envolvendo os campos de Arqueologia, Museologia e Conservação com o propósito de inventariar por inteiro o acervo arqueológico, bem como de aprimorar a conjuntura relacionada à conservação dos artefatos (ALCÂNTARA, 2016). 
Gráfico 3 - A faixa azul equivale aos períodos de atividade e a cor cinza, de descontinuidade na documentação museológica do museu

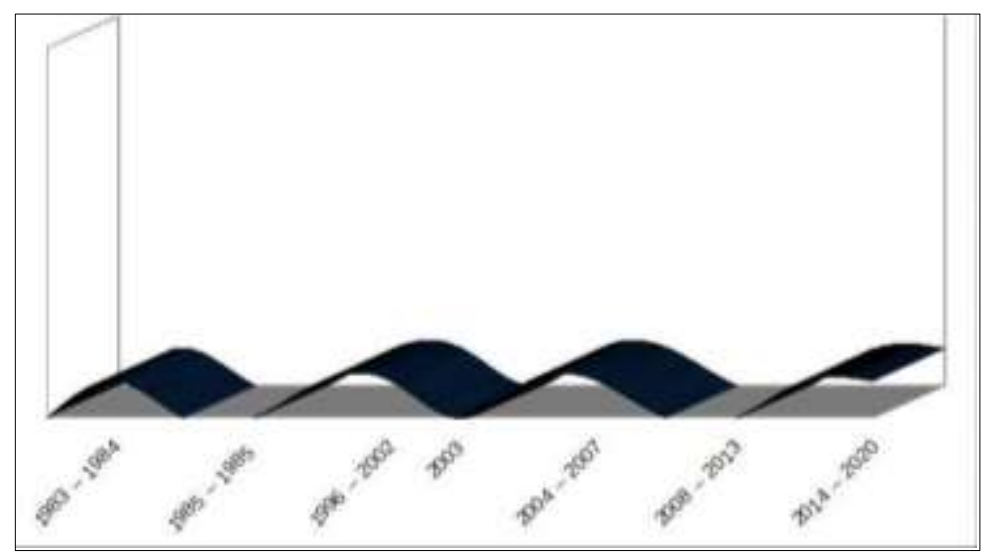

Fonte: Elaborado pela autora 1 (2020).
Figura 5 - Radiografia de paciente com escoliose

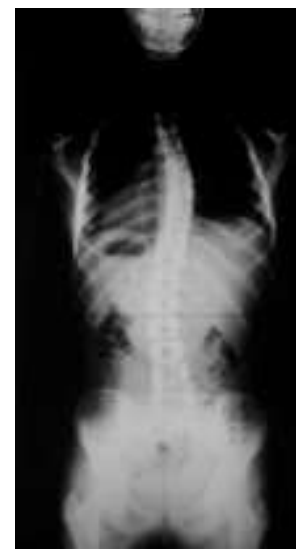

Fonte: Natour, 2004, p. 174.

A partir da análise dos dados sobre as atividades atreladas à documentação na esfera museológica dentro da instituição, desde sua criação até o momento, foi possível gerar o Gráfico 3, cujo aspecto assemelha-se à escoliose (Figura 5) na coluna vertebral em um exame de raioX, comum em até $30 \%$ dos casos de cifose de Scheuermann.

A análise do gráfico permite constatar que houve dois grandes períodos de inatividade na documentação da esfera museológica:

a. Entre 1985 e 1995, não apenas não houve entrada de coleções, como também o museu ainda não estava legalmente estabelecido;

b. Entre 2004 e 2007, o tratamento documental fundamentou-se nos parâmetros da Arquivologia, época em que o crescimento de coleções estava em um de seus picos;

c. De 2008 a 2013, as incorporações de coleções estavam no segundo auge e sucessivo declive, e sua documentação disponível, inclusive no que se refere à catalogação, é apenas a da Arqueologia, visto que o trabalho de documentação no museu foi descontinuado. 


\section{O raio-X: resultados encontrados}

A documentação museológica empregada nos primeiros anos tinha perspectiva estritamente museológica e considerou timidamente o uso de dois termos que atendessem a linguagem arqueológica. Ainda utilizava sistematização e conteúdos muito voltados para o parâmetro museológico, como o sistema numérico, que na década de 1980 foi amplamente usado em diferentes tipos de coleções, tais como artísticas, históricas, geológicas. Naquele momento, o prejuízo não foi tão manifesto em virtude de o material arqueológico não ter sido originário de investigações científicas, em sua maioria, e, portanto, não trazia questões, hipóteses e análises nem registros arqueológicos que compusessem, junto com as coleções, o patrimônio arqueológico incorporado.

Nesse ínterim, os danos mais visíveis foram as lacunas de dados mais gerais, apresentadas nas fichas de catalogação, principalmente relacionadas ao histórico, ao nome do sítio arqueológico, à função (todos esses impossíveis de registrar sem a fundamentação na pesquisa arqueológica e, claro, a bibliografia).

A reformulação da documentação realizou avanços concretos em diferentes sentidos e estava muito à frente dos padrões da época, considerando que em 1996 a interação entre documentação museológica e ao patrimônio arqueológico era incipiente. Isso porque, entre 1970 e meados de 1990, no campo museológico, os textos que tratavam de documentação de coleções no Brasil, em sua maioria, basicamente resumia-se as diretrizes do ICOM/UNESCO (1970), Camargo-Moro (1986), Ferrez e Bianchini (1987) e Ferrez (1994), de forma mais geral, e especificamente relacionada ao patrimônio arqueológico Bottallo (1998).

A metodologia utilizada partiu de um diagnóstico do trabalho realizado anteriormente. Prioritariamente foram identificados os problemas do ponto de vista da documentação museológica e a análise final demonstrou nas lacunas existentes a necessidade de realizar mudanças que também pareceram promissoras, devido ao reduzido montante de artefatos e à quantidade de coleções. Entre as atualizações na documentação, podem-se destacar:

a. A sistematização do acervo passa a ser em coleções e objetos, sobretudo porque na Arqueologia as coleções são incorporadas como tal, ou seja, não precisam ser arranjadas; 
b. O uso de distintos instrumentos de controle, desde os esboços de inventários até as fichas de registros geradas em base de dados, com a disponibilização de outras informações organizadas segundo a tipologia (audiovisual, memória oral ou documental), o que possibilitou a inserção dos dados que devem ser incorporados junto com os artefatos, como cadernos de campo, fotos, entrevistas, entre outros registros;

c. A criação de uma seção específica na ficha de registro com dados relacionados ao contexto do artefato, como por exemplo a origem, não contendo apenas o nome do sítio, mas também a localização exata em que foi retirado, identificada segundo o método de pesquisa empregado pelo arqueólogo, como visto na Figura 2, o metadado $\underline{\text { Subquadra/setor }}^{24}$.

Apesar desses avanços, algumas ponderações podem ser realizadas pensando numa perspectiva interdisciplinar entre Museologia e Arqueologia. Uma delas é que assim como "o arqueólogo pode estar tão concentrado em sua pesquisa que seus registros acabam sendo pertinentes apenas para si mesmo" (BALLARDO; MENDONÇA, 2018, p. 6003), compreendeu-se, a partir da análise baseada nesse estudo no MAE/UFBA, que o museólogo tão acumulado de atribuições ou talvez seguro do conhecimento técnico que realiza, pode não buscar a compreensão ou mesmo estreitar a comunicação com os processos de construção de conhecimento no campo arqueológico, deixando de cumprir uma das principais funções da documentação museológica: servir como fonte de pesquisa.

Essa questão ficou evidente ao analisar duas situações: a primeira, a criação da ficha de sítios, sem constatação de associação, aglutinação ou incorporação aos instrumentos documentais elaborados pelo contemporâneo CD/MAE; a segunda, a total desvinculação da catalogação numérica gerada pelo arqueólogo, precedente a incorporação, do sistema usado na documentação museológica, o que traz à tona uma questão muito mais abrangente, que é o problema da comunicação entre os profissionais das duas áreas: arqueólogos e museólogos.

Essa dificuldade de comunicação inicia com as terminologias e linguagens distintas que as áreas utilizam, que muitas vezes são tão demarcadas que criam disputas territoriais ou

24 Isso já esboça a ideia de que "os metadados criados na ficha de registro devem atender às prerrogativas do patrimônio arqueológico, que estão além de campos comuns a outros tipos de acervos como nome do objeto, número de registro, tipo de material, peso, dimensões. Faz-se necessário incluir itens como contexto arqueológico, localização no sítio, método de coleta (em vez de tipo de aquisição), descrição do sítio, e não apenas dos artefatos" (BALLARDO; MENDONÇA, 2018, p. 6009). 
"bairrismos", acentuando diferenças que criam verdadeiros abismos em vez de somar-se e resultar em contribuições para as disciplinas científicas envolvidas.

Um exemplo de que isso não se restringe a áreas próximas, como a Museologia e a Arqueologia, mas pode ocorrer inclusive dentro de um campo de investigação, é retratado na pesquisa de Rutz (2016, p. 23):

\footnotetext{
Quanto mais "especialistas" se tornam os "arqueólogos do lítico", maior a tendência de que seus resultados sejam apresentados em textos que apenas outros profissionais tão especializados sejam capazes de compreender. E, como acontece em outras ciências também, criou-se uma espécie de "idioma" próprio, que neste trabalho é chamado de "Litiquês".
}

Se da concepção de um profissional da Arqueologia existem distintos idiomas inseridos na disciplina científica, na ótica de quem busca a interdisciplinaridade entre áreas, eles figuram como fator crítico de distinção, de forma que um parece falar o "Museologuês" e o outro, o "Arqueologuês", do qual o "Litiquês" seria apenas um dos dialetos. Assim como ocorre em idiomas diferentes, uma mesma atividade pode ser designada por nomes diferentes. Por exemplo, o processo de fixação do código de identificação no corpo do artefato é denominado de marcação na esfera museológica, enquanto no âmbito da Arqueologia essa mesma ação é conhecida como catalogação, termo que para o "Museologuês" tem outro significado. Isso acarreta problemas de compreensão entre as duas áreas, principalmente durante o processo de documentação museológica, quando da inserção dos dados advindos dos relatórios de intervenção e outros documentos que acompanham as coleções arqueológicas incorporadas pela instituição, que podem ser erroneamente registrados dentro do âmbito museológico, se o profissional responsável não tiver essa clareza sobre o trabalho arqueológico.

Para isso, o profissional envolvido com as atividades de documentação museológica precisará mais que possuir um Thesaurus, enquanto "conjunto de conceitos ordenados", auxiliando no estabelecimento de relações entre os objetos, "definido segundo sua função ou estrutura" (FERREZ; BIANCHINI, 1987, p. XV). É necessário um especialista que trabalhe em conjunto, ajudando não apenas na tradução de termos, mas também na compreensão da formação do pensamento no outro idioma, porque afinal de contas, antes de aprender a falar outro idioma é preciso aprender a pensar nele. Mas e se não houver um especialista? Rutz (2016, p. 34) apontou os primeiros passos nesse processo de comunicação ao elaborar a cartilha "Traduzindo o Litiquês" para ajudar os que atuam na gestão de coleções a entender a linguagem técnica dos documentos que acompanham as coleções incorporadas, assim como, "na forma como consideram, armazenam e expõem artefatos líticos lascados”. 
Quando a articulação não é bilateral, resulta em lacunas como as apontadas nas ponderações sobre instrumentos documentais ou sistemas de registros desvinculados, criados separadamente para atender a parâmetros de cada uma das áreas, apresentados como palavras estrangeiras ("Arqueologuês") em um texto escrito em outra língua ("Museologuês").

Por fim, uma última reflexão está ligada à descontinuidade do trabalho que foi iniciado a partir da segunda reestruturação da documentação, cuja recuperação do espólio do Centro de Documentação se tornou uma fonte de acervo documental. Contudo, o direcionamento para uma concepção científica ligada aos parâmetros arquivísticos, transferiu questões mais específicas, como métodos, procedimentos e outros registros que compõem o patrimônio arqueológico e ingressou na instituição junto com o testemunho material recolhido, para o tratamento próprio do campo arqueológico.

Na perspectiva atual, a instituição conta com servidores especializados em Museologia e Arqueologia, o que pode facilitar o diálogo e a comunicação, e propiciando um emparelhamento entre as coleções arqueológicas e a documentação museológica.

\section{Considerações finais}

A partir da análise do trabalho desenvolvido na documentação museológica do MAE/UFBA, notou-se que, ao estabelecer um sistema documental e o ordenamento das coleções, é imprescindível considerar quais dados são significativos para a pesquisa arqueológica e de que maneira eles podem estar acessíveis.

Para isso, faz-se necessário compreender a terminologia e o processo de trabalho desenvolvido na Arqueologia. E, dessa forma, mais do que usar palavras do vocabulário do "Arqueologuês" para descrever e nomear artefatos, vincular a documentação arqueológica desde o tratamento que o pesquisador concede a esses dados, tais como o sistema de registro elaborado em campo ou no laboratório de análise, assim como as relações dos artefatos com o contexto arqueológico - ao processo de documentação museológica.

Assim como no tratamento da coluna vertebral acometido por uma cifose e escoliose precisa passar por diagnóstico para saber o grau de desenvolvimento da enfermidade e o histórico de tratamentos efetuados, o mesmo ocorre com a documentação das coleções do MAE/UFBA. 
A reestruturação sistemática e organizacional da dinâmica documental da instituição deve estar fundamentada num diagnóstico das coleções e do sistema precedente, não apenas para detectar incoerências ou falhas, mas também para determinar se é necessária uma requalificação ou a total substituição.

O exame preliminar aponta que, com alguns ajustes, é possível tratar do grande quantitativo das coleções arqueológicas, cuja "cifose" já foi estabilizada desde de 2014, com a suspensão da incorporação de coleções, dando continuidade ao trabalho realizado anteriormente pelo $\mathrm{CD} / \mathrm{MAE}$ tratando das coleções como parte do patrimônio, concebido a partir de sua vinculação aos documentos escritos, orais, audiovisuais ou de outra natureza.

A cifose tornou-se visível apenas depois de 12 anos, como ocorre com o portador de Scheuermann, quando o MAE/UFBA passou a receber um grande quantitativo de material arqueológico, principalmente a partir da Arqueologia Preventiva. Associado a cifose, observouse uma espécie de escoliose, comum aos portadores da doença, ao analisar a irregularidade das atividades documentais nas coleções museológicas, desencadeando uma sinuosidade similar aos desvios nas placas terminais da coluna vertebral, deixando de proporcionar $\mathrm{o}$ amortecimento de impactos do uso das coleções, assim como ocorre com o desgaste natural da coluna vertebral.

Essas questões relacionadas acima, e ainda, a suspensão de novas entradas no acervo, em 2014 e a admissão de uma profissional em Arqueologia no quadro da instituição, tornaram a gestão de coleções o foco para o museu. Mas para realizar essa tarefa que demanda grande esforço, faz-se necessário compreender como a instituição tinha realizado essa atividade ao longo de todos esses anos de existência.

O caminho para esse tratamento já foi traçado com a formação de uma equipe interdisciplinar dispondo de profissionais de Arqueologia e da Museologia, que a partir da articulação de seus conhecimentos podem estabelecer uma base de comunicação que fundamente um sistema documental utilizado cabalmente como fonte de informação. 


\section{Referências}

ALCÂNTARA, T. M. O acervo arqueológico do MAE/UFBA. Boletim Informativo do Museu de Arqueologia e Etnologia, Salvador, n. 11, Ano 3, p. 5, fev./jul. 2016.

ALMEIDA, F. L. Reflexões sobre coleções etnográficas a partir da coleção "Maria Ignez Mello" de objetos wauja do MAE-UFPR. XIII Reunião de Antropologia do Mercosul 22 a 25 de Julho de 2019 - Porto Alegre (RS). Disponível em: https://www.ram2019.sinteseeventos.com.br/ Acesso em: 27 abr. 2020.

BALLARDO, L. O. M. Documentação museológica: a elaboração de um sistema documental para acervos arqueológicos e sua aplicação no Laboratório de Estudos e Pesquisas Arqueológicas/UFSM. 2013. 125f. Dissertação (Pós-Graduação Profissionalizante em Patrimônio Cultural) - Universidade Federal de Santa Maria, Santa Maria, Rio Grande do Sul, 2013.

BALLARDO, L. M.; MENDONCA, E. C. Struthioniformes e paquidermes: considerações sobre a musealização do patrimônio arqueológico em instituições de salvaguarda. In: ENCONTRO NACIONAL DE PESQUISA EM CIÊNCIA DA INFORMAÇÃO, 19., 2018, Londrina. Anais [...]. Londrina: ANCIB, 2018. p. 5998-6017.

BRASIL. Ministério da Cultura. IPHAN. Portaria nº 07, de 01 de dezembro de 1988. Estabelece os procedimentos necessários à comunicação prévia, às permissões e às autorizações para pesquisas e escavações arqueológicas em sítios arqueológicos previstas na Lei n 3.924, de 26 de julho de 1961. Diário Oficial da União, Brasília, 15 dez. 1988.

BOTTALLO, M. As coleções de arqueologia pré-colonial brasileira do MAE/USP: um exercício de documentação Museológica. Revista do Museu de Arqueologia e Etnologia, São Paulo, n. 8, p. 257-268, 1998.

BOTTALLO, M. Diretrizes em Documentação Museológica. In: FELIX, I.; PAZIN, M. (eds.). Documentação e conservação de acervos museológicos: diretrizes. São Paulo: Governo de São Paulo; ACAM Portinari, p. 48-79, 2010.

CALDARELlI, S. B.; CÂNDIDO, M. M. D. Desafios da Arqueologia preventiva: como gerir e socializar o imenso volume de materiais e documentos por ela produzidos? Revista Arqueologia Pública, Campinas, v. 11, n. 2, p. 186-214, 2017. Disponível em: https://www.researchgate.net/publication/322966987_Desafios_da_Arqueologia_Preventiva como_gerir_e_socializar_o_imenso_volume_de materiais_e_documetos_por_ela_produzido. Acesso em: 10 dez. 2018.

CAMARGO-MORO, Fernanda. Museu: aquisição-documentação: tecnologias apropriadas para a preservação de bens culturais. Rio de Janeiro: Livraria Eça, 1986.

CÂNDIDO, M. I. Documentação Museológica. In: CADERNO de diretrizes museológicas I. Belo Horizonte: Secretaria de Estado da Cultura/Superintendência de Museus, 2002. p. 33-92.

CERÁVOLO, S.; CUNHA, C. Fichas Índice e listagens de documentos: guia do arquivo institucional do MAE-UFBA. 2007. v. 2. 
CERÁVOLO, S.; CUNHA, C. Relatório de atividades inventário de coleções arqueológicas do Museu de Arqueologia e Etnologia da Universidade Federal da Bahia: Núcleo de Documentação e Referência (NDR/MAE). jan. 2008.

CERÁVOLO, S.; CUNHA, C. Relatório e proposta de re-organização do acervo documental do MAE-UFBa. Núcleo de Documentação e Referência (NDR/MAE). fev. 2006.

BRASÍLIA. Currículo do sistema de Currículos Lattes. Conselho Nacional de Desenvolvimento Científico e Tecnológico. Informações sobre a doutora Rosana Andrade Dias do Nascimento. 2020. Disponível em: http://lattes.cnpq.br/4874268042003853. Acesso em: 12 ago. 2020.

BRASÍLIA. Currículo do sistema de Currículos Lattes. Conselho Nacional de Desenvolvimento Científico e Tecnológico. Informações sobre a doutora Suely Moraes Ceravolo. 2020. Disponível em: http://lattes.cnpq.br/3520955054532444. Acesso em: 12 ago. 2020.

BRASÍLIA. Currículo do sistema de Currículos Lattes. Conselho Nacional de Desenvolvimento Científico e Tecnológico. Informações sobre o doutor Carlos Alberto Santos Costa. 2020. Disponível em: http://lattes.cnpq.br/8375227365744890. Acesso em: 12 ago. 2020.

COSTA, C. A. S. Proposta de instrumento documental museológico complementar para as coleções arqueológicas do MAE-UFBA. Revista eletrônica Jovem Museologia: Estudos sobre museus, Museologia e Patrimônio. Rio de Janeiro, v. 2, n. 4, p. 4-23, 2007.

DREWETT, Peter. Field archaeology: an introduction. London: UCL, 1999.

FERREZ, H. D. Documentação museológica: teoria para uma boa prática. Cadernos de Ensaio: Estudos de Museologia, Rio de Janeiro, n. 2, p. 65-74, 1994.

FERREZ, Helena Dodd; BIANCHINI, Maria Helena. S. Thesaurus para acervos musicológicos. Rio de janeiro: Minc/SPHAN/Fundação Nacional Pró-Memória/MHN. Coordenadoria Geral de Acervos Museológicos, 1987. 2 v. 482 p.

ICOM/UNESCO. Ética de aquisições. Paris: International Council of Museuns, 1970.

KNOPLICH, José. Viva bem com a coluna que você tem. 32. ed. Baureri. Manole, 2016.

LIMA, D. F. C. Herança cultural (re)interpretada ou a memória social e a instituição museu: releitura e reflexões. Revista Eletrônica do Programa de Pós-Graduação em Museologia e Patrimônio, Rio de Janeiro, v. 1, n. 1, p. 33-43, 2008. Texto baseado em paper (1997) apresentado no Simpósio ICOFOM (ICOM) Museologia e Memória. Disponível em: http://revistamuseologiaepatrimonio.mast.br/index.php/ppgpmus/article/view/4/2. Acesso em: 21 dez. 2018.

MENDONÇA, E. C. Musealização do patrimônio arqueológico em Sergipe: um estudo sobre endosso institucional e gestão de acervos coletados. In: ENCONTRO NACIONAL DE PESQUISA EM CIÊNCIA DA INFORMAÇÃO, 13., 2012, Rio de Janeiro. Anais [...]. Rio de Janeiro: Fundação Oswaldo Cruz, 2012. p. 1-18. 
NASCIMENTO, R. A. D. O museu de Arqueologia e etnologia da Universidade Federal da Bahia. Seminários de capacitação museológica. Anais..., Belo Horizonte, ICFG, 2004. v. I, p. 267-270.

NATOUR, J. Coluna vertebral-conhecimentos básicos. 2. ed. São Paulo: ETCetera, 2004.

PADILHA, R. C. Documentação museológica e gestão de acervo. Coleção Estudos Museológicos, Florianópolis, v. 2, 2014.

PASSOS, A. M. de O. O acervo etnológico do MAE/UFBA. Boletim Informativo do Museu de Arqueologia e Etnologia, Salvador, n. 11, ano 3, p. 7, fev./jul. 2016.

PEREIRA, L. C. 30 anos do MAE-UFBA. Boletim Informativo do Museu de Arqueologia e Etnologia, Salvador, n. 6, ano 2, p. 1, ago. 2013/jan. 2014.

PINHEIRO, L. V. R. Campo disciplinar da ciência da informação: fronteiras remotas e recentes. In: PINHEIRO, L. V. R. (org.). Ciência da informação, ciências sociais e interdisciplinaridade. Brasília; Rio de Janeiro: Instituto Brasileiro de Informação em Ciência e Tecnologia, p. 155-178, 1999.

RAPOSO, L.; MARTINS, A. S.; CORREIA, V. Arqueologia. Normas de inventário. Lisboa: Instituto Português de Museus, 2000.

RUTZ, C. Uma abordagem comunicativa em arqueologia: traduzindo o Litiquês. 2016. 127f. Dissertação (Pós-Graduação Profissionalizante em Patrimônio Cultural) - Universidade Federal de Santa Maria, Santa Maria, Rio Grande do Sul, 2016.

SANTOS, H. R. S. dos. Patrimônio arqueológico musealizado em Sergipe: um estudo de caso sobre a relação documentação museológica e informação arqueológica como procedimento essencial de gestão de coleções. 2015. 140 f. Dissertação (Pós-Graduação em Arqueologia) - Universidade Federal de Sergipe, Laranjeiras, 2015.

SANTOS, M. C. T. M. Um compromisso social com a museologia. Revista Cadernos do CEOM, Santa Catarina, v. 27, n. 41, p. 71-114, dez. 2014.

SOARES, C. A. C.; ETCHEVARNE, C. A.; MENDONÇA, T. C. S. Catálogo do Museu de Arqueologia e Etnologia. Brasília: Ministério de Relações Exteriores, Itamarati, 2006.

VASCONCELOS, M. L. C.; ALCÂNTARA, T. M. Com quantas caixas se faz uma reserva técnica?: um relato de experiência sobre a gestão dos acervos arqueológicos no MAE/UFBA. Revista de Arqueologia Pública: Campinas, v. 11, n. 2, p. 153-165, nov. 2017.

UNIVERSIDADE FEDERAL DA BAHIA. Ata da Sessão do Conselho Universitário realizada em 07 de abril de 1995. 07 abr. 1995. Disponível em: https://cparq.ufba.br/ata-dasessao-do-conselho-universitario-realizada-em-07-de-abril-de-1995. Acesso em: 16 abr. 2020. 